\title{
Sensitivity of Single Membrane-Spanning $\alpha$-Helical Peptides to Hydrophobic Mismatch with a Lipid Bilayer: Effects on Backbone Structure, Orientation, and Extent of Membrane Incorporation ${ }^{\dagger}$
}

\author{
Maurits R. R. de Planque, ${ }^{*}, \risingdotseq$ Erik Goormaghtigh, ${ }^{\S}$ Denise V. Greathouse, ${ }^{\|}$Roger E. Koeppe II, \\ John A. W. Kruijtzer,${ }^{\perp}$ Rob M. J. Liskamp, ${ }^{\perp}$ Ben de Kruijff, $₫$ and J. Antoinette Killian
}

\begin{abstract}
Department of Biochemistry of Membranes, Center for Biomembranes and Lipid Enzymology, Institute of Biomembranes, Utrecht University, Padualaan 8, 3584 CH Utrecht, The Netherlands, Laboratoire de Chimie-Physique des Macromolécules aux Interfaces, Université Libre de Bruxelles, Campus Plaine, B1050 Brussels, Belgium, Department of Medicinal Chemistry, Utrecht University, Sorbonnelaan 16, 3584 CA Utrecht, The Netherlands, and Department of Chemistry and Biochemistry, University of Arkansas, Fayetteville, Arkansas 72701
\end{abstract}

Received April 10, 2000; Revised Manuscript Received February 5, 2001

\begin{abstract}
The extent of matching of membrane hydrophobic thickness with the hydrophobic length of transmembrane protein segments potentially constitutes a major director of membrane organization. Therefore, the extent of mismatch that can be compensated, and the types of membrane rearrangements that result, can provide valuable insight into membrane functionality. In the present study, a large family of synthetic peptides and lipids is used to investigate a range of mismatch situations. Peptide conformation, orientation, and extent of incorporation are assessed by infrared spectroscopy, tryptophan fluorescence, circular dichroism, and sucrose gradient centrifugation. It is shown that peptide backbone structure is not significantly affected by mismatch, even when the extent of mismatch is large. Instead, this study demonstrates that for tryptophan-flanked peptides the dominant response of a membrane to large mismatch is that the extent of incorporation is reduced, when the peptide is both too short and too long. With increasing mismatch, a smaller fraction of peptide is incorporated into the lipid bilayer, and a larger fraction is present in extramembranous aggregates. Relatively long peptides that remain incorporated in the bilayer have a small tilt angle with respect to the membrane normal. The observed effects depend on the nature of the flanking residues: long tryptophan-flanked peptides do not associate well with thin bilayers, while equisized lysine-flanked peptides associate completely, thus supporting the notion that tryptophan and lysine interact differently with membrane-water interfaces. The different properties that aromatic and charged flanking residues impart on transmembrane protein segments are discussed in relation to protein incorporation in biological systems.
\end{abstract}

Membrane structure and function are modulated by the interactions between proteins and lipids. It has been demonstrated that a key factor in such protein-lipid interplay is the extent of hydrophobic matching between these two membrane constituents. Hydrophobic matching influences, e.g., integral membrane protein activity $(1-5)$, membrane microdomain formation $(6-8)$, and protein sorting in the secretion pathway $(9,10)$. Processes such as these could be driven by a tendency of a membrane to rearrange its components in order to obtain an energetically favorable matching situation $(11-14)$.

$\dagger$ This work was supported by the Council for Chemical Sciences (CW) with financial aid from The Netherlands Organization for Scientific Research (NWO), by EU TMR Network ERBFMRX-CT960004, by NIH Grant GM 34968 (to R.E.K. and D.V.G.), and by NATO Grant CRG 950357.

* Corresponding author. Telephone: +61 38344 3931. Fax: + 61 39347 5180. E-mail: mdp@unimelb.edu.au.

Department of Biochemistry of Membranes, Utrecht University.

$\S$ Université Libre de Bruxelles.

"University of Arkansas.

${ }^{\perp}$ Department of Medicinal Chemistry, Utrecht University.
To establish such a matching situation, several adaptations of protein and lipid conformation, orientation, and aggregational state can be envisaged (reviewed in ref 14). To understand what type of protein and/or lipid adaptation is indeed relevant, the response of a membrane to an imposed hydrophobic mismatch can be used. This requires welldefined systems in which lipid as well as protein hydrophobic length can be varied. To this end, synthetic hydrophobic peptides of different lengths, flanked either by tryptophan or by lysine residues, have been studied in phospholipid model membranes by several groups (14-20). These peptides can be viewed as consensus membrane spanners, because transmembrane segments of proteins generally consist of a hydrophobic core that is preferentially flanked on both sides by aromatic and/or charged amino acids $(21-23)$.

We have shown earlier using Trp-flanked membranespanning peptides that lipids will systematically adapt bilayer thickness as a response to hydrophobic mismatch (24): relatively short Trp-flanked analogues are capable of decreasing bilayer thickness, and relatively long Trp-flanked peptides can increase the bilayer thickness. However, the changes in 


\begin{tabular}{ccc}
\hline Table 1: Amino Acid Sequences of the Peptides Used and Calculated Length of the Leucine-Alanine Stretch When Present as an $\alpha$-Helix ${ }^{a}$ & $\begin{array}{c}\text { length of } \\
\text { LA stretch }(\AA)\end{array}$ \\
\hline & & sequence \\
peptide & Ac-GWWLALALALALAWWA-Etn & 15.0 \\
WALP16 & Ac-GWWLALALALALALALWWA-Etn & 19.5 \\
WALP19 & Ac-GWWLALALALALALALALWWA-Etn & 22.5 \\
WALP21 & Ac-GWWLALALALALALALALALWWA-Etn & 25.5 \\
WALP23 & Ac-GWWLALALALALALALALALALWWA-Etn & 28.5 \\
WALP25 & Ac-GWWLALALALALALALALALALALWWA-Etn & 31.5 \\
WALP27 & Ac-GWWLALALALALALALALALALALALALWWA-Etn & 37.5 \\
WALP31 & Ac-GKKLALALALALALALALALKKA-amide & 25.5 \\
KALP23 & Ac-GKKLALALALALALALALALALALALALKKA-amide & 37.5 \\
KALP31 & & \\
\hline
\end{tabular}

${ }^{a}$ It is assumed that each amino acid has a length of $1.5 \AA$.

lipid length were insufficient to compensate entirely for the peptide-lipid mismatch. These observations raise the important questions of whether a partial mismatch is tolerated and/or whether the peptide components of the membrane also compensate for mismatch situations.

In this study, we investigated by attenuated total reflection infrared spectroscopy (ATR-FTIR) ${ }^{1}$ the peptide backbone conformation and orientation under mismatch conditions. A set of Trp-flanked poly(leucine-alanine) peptides with different hydrophobic lengths was used. These analogues were incorporated in planar phosphatidylcholine bilayers of varying thickness to cover a large range of mismatch situations, and the peptide amide I signal was used to characterize the different peptides in their membrane environment.

The results show that the peptide backbone forms a welldefined $\alpha$-helix under all conditions. ATR-FTIR experiments with polarized light suggest that a minor peptide tilt with respect to the membrane normal occurs when the peptides are relatively long. However, from amide I intensities and together with results from fluorescence, circular dichroism, and sucrose density gradient experiments, it can be concluded that the main response of the peptide-lipid system to hydrophobic mismatch is the exclusion of a significant amount of peptide from the bilayer, regardless of whether the peptide is too long or too short.

To allow comparison of the effects of Trp with those of Lys as another frequently occurring flanking residue, we also investigated the membrane association properties of Lysflanked peptides that are completely analogous to the Trpflanked peptides used in this study. It was found that a larger fraction of Lys-flanked peptides than of Trp-flanked peptides can be accommodated in thin bilayers. These observations support the concept that Trp and Lys anchoring residues have different roles in protein-membrane interactions (19). Such interactions may govern protein incorporation in biological systems.

\footnotetext{
${ }^{1}$ Abbreviations: ATR-FTIR, attenuated total reflection Fourier transform infrared; NMR, nuclear magnetic resonance; ESR, electron spin resonance; $\mathrm{CD}$, circular dichroism; FAB-MS, fast atom bombardment mass spectrometry; ES-MS, electrospray mass spectrometry; Ac, acetyl; Etn, ethanolamine; TFA, trifluoroacetic acid; TFE, trifluoroethanol; WALP, tryptophan-alanine-leucine peptide $\mathrm{Ac}-\mathrm{GW}_{2}(\mathrm{LA})_{n} \mathrm{~W}_{2} \mathrm{~A}$ Etn; KALP, lysine-alanine-leucine peptide $\mathrm{Ac}-\mathrm{GK}_{2}(\mathrm{LA}){ }_{n} \mathrm{~K}_{2} \mathrm{~A}$-amide; PC, phosphatidylcholine; 14:1 $\mathrm{c}$-PC, 1,2-dimyristoleoyl-sn-glycero-3phosphocholine; 16:1 $1_{\mathrm{c}} \mathrm{PC}$, 1,2-dipalmitoleoyl-sn-glycero-3-phosphocholine; 18:1 1 -PC, 1,2-dioleoyl-sn-glycero-3-phosphocholine; 20:1 $1_{\mathrm{c}}$-PC, 1,2-dieicosenoyl-sn-glycero-3-phosphocholine; 22:1 1 -PC, 1,2-dierucoyl$s n$-glycero-3-phosphocholine; 14:0-PC, 1,2-dimyristoyl-sn-glycero-3phosphocholine; $\mathrm{L}_{\alpha}$, liquid crystalline bilayer lipid phase.
}

\section{MATERIALS AND METHODS}

\section{Materials}

WALP and KALP peptides (see Table 1) were synthesized as described before $(19,25)$. When necessary $(<90 \%$ purity, as judged by HPLC), WALP peptides were purified by HPLC using a Nucleosil Si 100-10 column (Machery Nagel) and chloroform/methanol/water $(80 / 19 / 1 \mathrm{v} / \mathrm{v} / \mathrm{v})$ as eluent. KALP peptides were analyzed using an automatic HPLC system (Gilson) with an analytical reversed-phase $\left(\mathrm{C}^{4}\right)$ column (Altech Adsorbosphere XL C ${ }^{4}, 5 \mu \mathrm{m}$ particle size, $300 \AA$ pore diameter, $250 \times 4.6 \mathrm{~mm}$ column size). Elution of peptides was effected at a flow rate of $1 \mathrm{~mL} / \mathrm{min}$ using a linear gradient of $100 \%$ of $0.1 \%$ TFA in water to $100 \%$ of $0.085 \% \mathrm{TFA}$ in acetonitrile/water (95/5 v/v) in $20 \mathrm{~min}$. The identity and purity of all peptides were checked by FABMS or ES-MS. Out of practical considerations, WALP and KALP peptide families have different C-terminal moieties. As a control, WALP19 was synthesized with the same C-terminal amide as is present in the KALP peptides. This WALP analogue behaved identically to the WALP19 peptides with a C-terminal ethanolamine moiety (data not shown). All phospholipids were purchased from Avanti Polar Lipids Inc. (Birmingham, AL).

\section{Methods}

Sample Preparation. Unless stated otherwise, peptides were dissolved in $0.5 \mathrm{~mL}$ of TFE and added to $0.5 \mathrm{~mL}$ of a lipid suspension in methanol, followed by drying in a rotary evaporator and overnight incubation under high vacuum. WALP analogues were quantified by the absorbance of tryptophan at $280 \mathrm{~nm}$ (using a molar extinction coefficient $\epsilon$ of $22400 \mathrm{M}^{-1} \mathrm{~cm}^{-1}$ ) and KALP peptides by their dry weight. The peptide/lipid molar ratio in all samples was $1 / 30$. Subsequently, samples were hydrated, the details of which depended on the particular measurement (see below). This mixed film procedure generally results in optimal solubilization of hydrophobic peptides in lipid bilayers.

ATR-FTIR Measurements. Germanium crystal plates (50 $\times 20 \times 2 \mathrm{~mm}$, Harrick EJ2121) were cleaned by washing with distilled water, methanol, and chloroform, respectively, and subsequently placed for $5 \mathrm{~min}$ in a Plasma Cleaner PDC23G (Harrick Scientific, Ossining, NY) in order to obtain a hydrophilic surface. Dried peptide-lipid films containing 35 nmol of peptide and $1050 \mathrm{nmol}$ of lipid were hydrated in $200 \mu \mathrm{L}$ of distilled water, and the resulting suspension was vortexed. A $20-40 \mu \mathrm{L}$ aliquot of such a sample was spread 
on the plates, and excess water was removed under a nitrogen flow. The plates were placed under an aperture angle of $45^{\circ}$, yielding 25 internal reflections. ATR-FTIR spectra were recorded at room temperature on a Bruker IFS 55 infrared spectrophotometer equipped with a liquid nitrogen cooled mercury cadmium telluride detector at a nominal resolution of $4 \mathrm{~cm}^{-1}$, encoding for every $1 \mathrm{~cm}^{-1}$ in the range $800-$ $4000 \mathrm{~cm}^{-1}$. Each spectrum is an average of 128 scans, simultaneously corrected for the background using a clean germanium plate. The spectrophotometer was continuously purged with air dried on a Whatman 75-62 air dryer to minimize the spectral contribution of atmospheric water. Residual water vapor peaks were subtracted using reference data, and baseline correction was applied when necessary.

Analysis of ATR-FTIR Spectra. The amide I band was curve-fitted with a Gaussian band shape, using the Origin Peak Fitting Module 3.5 from Microcal Software Inc. (Northampton, MA), to establish the wavenumber corresponding to maximum band intensity with an uncertainty of less than $0.1 \mathrm{~cm}^{-1}$. Prior to this procedure the appropriate pure lipid spectrum, scaled to the same lipid carbonyl vibration intensity, was subtracted from the spectra of peptidecontaining samples, to eliminate nonpeptide contributions in the amide I spectral region. To establish the spectral contribution of a given WALP peptide in different PC systems, the area of the amide I peak was divided by the area of the lipid $\mathrm{C}=\mathrm{O}$ peak. Peptides with a larger number of amide bonds generally cause a more intense amide I signal. To compare peptides of different lengths, the obtained spectral peptide/lipid ratio was therefore divided by the number of amide groups present in the peptide to yield a relative amide I intensity.

ATR-FTIR Dichroism and Peptide Orientation. Spectra were recorded with parallel and perpendicular polarized incident light (with respect to the incidence plane) and were scaled to the same lipid carbonyl vibration intensity. For welloriented bilayers, the dichroic ratio of the resulting amide I intensities is related to the mean angle between the $\mathrm{C}=\mathrm{O}$ dipole moment and the plate surface. Considering a $27^{\circ}$ angle between the $\mathrm{C}=\mathrm{O}$ dipole moment and the long axis of an $\alpha$-helix, the mean angle between the helix axis and the plate normal ("helix tilt angle") was calculated by earlier described methods $(26,27)$. The thickness of the membrane film, one of the parameters required for this procedure $(28,29)$, was derived from the dichroic ratio of the lipid $v(\mathrm{C}=\mathrm{O})$ band $(26,27)$.

Circular Dichroism. Dry peptide-lipid films containing $15 \mu \mathrm{mol}$ of lipid were prepared as described above. For practical reasons, KALP/PC samples were hydrated in $1 \mathrm{~mL}$ of buffer (100 mM NaCl, $25 \mathrm{mM}$ Tris, pH 7.4) and WALP/ $\mathrm{PC}$ samples in $1 \mathrm{~mL}$ of distilled water. After vortexing and freeze-thawing, the samples were centrifuged at $30000 \mathrm{~g}$ for $15 \mathrm{~min}$ at $4{ }^{\circ} \mathrm{C}$, and the supernatant was removed. The samples were then sonicated for $5 \mathrm{~min}$ with a $50 \%$ duty cycle and with an input power of $40 \mathrm{~W}$, using a Branson 250 tip sonicator. To pellet down titanium particles and any residual multilamellar lipid structures, the sonicated samples were next centrifuged at $30000 \mathrm{~g}$ for $15 \mathrm{~min}$ at $4{ }^{\circ} \mathrm{C}$. Measurements were carried out at room temperature on a Jasco J-600 spectropolarimeter, using a $0.2 \mathrm{~mm}$ path length cell, $1 \mathrm{~nm}$ bandwidth, $0.2 \mathrm{~nm}$ resolution, $1 \mathrm{~s}$ response time, and a scan speed of $20 \mathrm{~nm} / \mathrm{min}$. Control experiments showed that
WALP/PC dispersions in buffer yielded identical spectra as WALP/PC dispersions in distilled water (data not shown).

Fluorescence Measurements. Five microliters of a sample prepared for FTIR measurements was added to $1.5 \mathrm{~mL}$ of distilled water, vortexed, and subsequently sonicated and centrifuged under the same conditions as described for CD samples. A total of $1.2 \mathrm{~mL}$ of the resulting clear solution was transferred to a quartz cuvette $(1 \mathrm{~cm}$ excitation path length and $4 \mathrm{~mm}$ emission path length) at room temperature. Tryptophan fluorescence was measured on a Perkin-Elmer luminescence spectrometer LS 50B, using a $2.5 \mathrm{~mm}$ excitation slit and $5.0 \mathrm{~mm}$ emission slit. The tryptophan residues were excited at $280 \mathrm{~nm}$, and the emission in the 300-400 $\mathrm{nm}$ region was recorded. The contribution of pure lipid samples was subtracted from the obtained signal.

Alternative Sample Preparation Methods for Fluorescence Measurements. Lipid and peptide stock solutions were prepared with respective concentrations of 800 and $26.7 \mu \mathrm{M}$, enabling the addition of peptide and lipid solutions to each other in equal volumes, while maintaining a 1/30 peptide/ lipid molar ratio. For the mixed film methods, $100 \mu \mathrm{L}$ of peptide stock solution in TFE or ethanol was added to 100 $\mu \mathrm{L}$ of lipid stock solution in TFE, methanol, or ethanol. The mixture was vortexed, dried under a nitrogen flow, and further dried overnight under high vacuum. The resulting peptide-lipid film was hydrated with $1200 \mu \mathrm{L}$ of distilled water. For the lyophilization procedure, $100 \mu \mathrm{L}$ of lipid in methanol was dried under a nitrogen flow and under high vacuum. Subsequently, $100 \mu \mathrm{L}$ of distilled water was used to hydrate and disperse the lipid film, and $100 \mu \mathrm{L}$ of peptide in TFE was added to this liposome suspension, disrupting the bilayers. An excess of $1 \mathrm{~mL}$ of distilled water was added to re-form the disrupted liposomes, and this was followed by immediate lyophilization. The resulting powder was hydrated with $1200 \mu \mathrm{L}$ of distilled water. For the ethanol dilution procedure, $100 \mu \mathrm{L}$ of peptide in ethanol and 100 $\mu \mathrm{L}$ of lipid in ethanol were mixed and dried under a nitrogen flow. The peptide-lipid film was redissolved in $30 \mu \mathrm{L}$ of ethanol, to which $1170 \mu \mathrm{L}$ of distilled water was added. All suspensions were sonicated and centrifugated to remove residual multilamellar structures and peptide aggregates. For fluorescence measurements, $1 \mathrm{~mL}$ of the sample was diluted with $1 \mathrm{~mL}$ of distilled water, resulting in a final peptide concentration of $1.1 \mu \mathrm{M}$, in case that all peptide remains in the supernatant.

Sucrose Density Gradient Centrifugation. Dried peptidelipid films (containing $10 \mu \mathrm{mol}$ of lipid) were hydrated in 1 $\mathrm{mL}$ of distilled water and layered on top of a linear sucrose gradient $\left[5.5-17.5 \%\left(14: 1_{\mathrm{c}}\right.\right.$-PC samples) or $0-8.0 \%$ (22: $1_{\mathrm{c}}$-PC samples), with a total volume of $\left.9 \mathrm{~mL}\right]$. The samples were centrifugated for $20 \mathrm{~h}$ at $150000 \mathrm{~g}$ at $25{ }^{\circ} \mathrm{C}$ in a Beckman SW41 rotor. Separate bands were isolated, and their macroscopic lipid organization was established by solid-state ${ }^{31} \mathrm{P}$ NMR measurements, as described earlier (30). The peptide content of the bands was determined by UV absorbance at $280 \mathrm{~nm}$, after dilution of the sample with methanol, and the lipid content was determined according to Rouser et al. (31).

\section{RESULTS}

Effect of Hydrophobic Mismatch on Peptide Backbone Conformation. To systematically explore whether the peptide 
Table 2: Hydrophobic Thickness of the Various

Phosphatidylcholine Bilayers in the $\mathrm{L}_{\alpha}$ Phase $^{a}$

\begin{tabular}{cccc}
\hline lipid & $\begin{array}{c}\text { hydrophobic } \\
\text { thickness }(\AA)\end{array}$ & lipid & $\begin{array}{c}\text { hydrophobic } \\
\text { thickness }(\AA)\end{array}$ \\
\hline C14:0-PC & $23^{b}$ & $\mathrm{C} 18: 1_{\mathrm{c}}-\mathrm{PC}$ & $27^{b}$ \\
$\mathrm{C} 14: 1_{\mathrm{c}}-\mathrm{PC}$ & $20^{c}$ & $\mathrm{C} 20: 1_{\mathrm{c}}-\mathrm{PC}$ & $30.5^{c}$ \\
$\mathrm{C} 16: 1_{\mathrm{c}}-\mathrm{PC}$ & $23.5^{b}$ & $\mathrm{C} 22: 1_{\mathrm{c}}-\mathrm{PC}$ & $34^{b}$ \\
\hline
\end{tabular}

${ }^{a}$ Hydrophobic thickness is defined as the distance between the acyl chain C-2 atoms of two opposing lipids in a lipid bilayer. ${ }^{b}$ See ref 34. ${ }^{c}$ Extrapolation from data in ref 34.

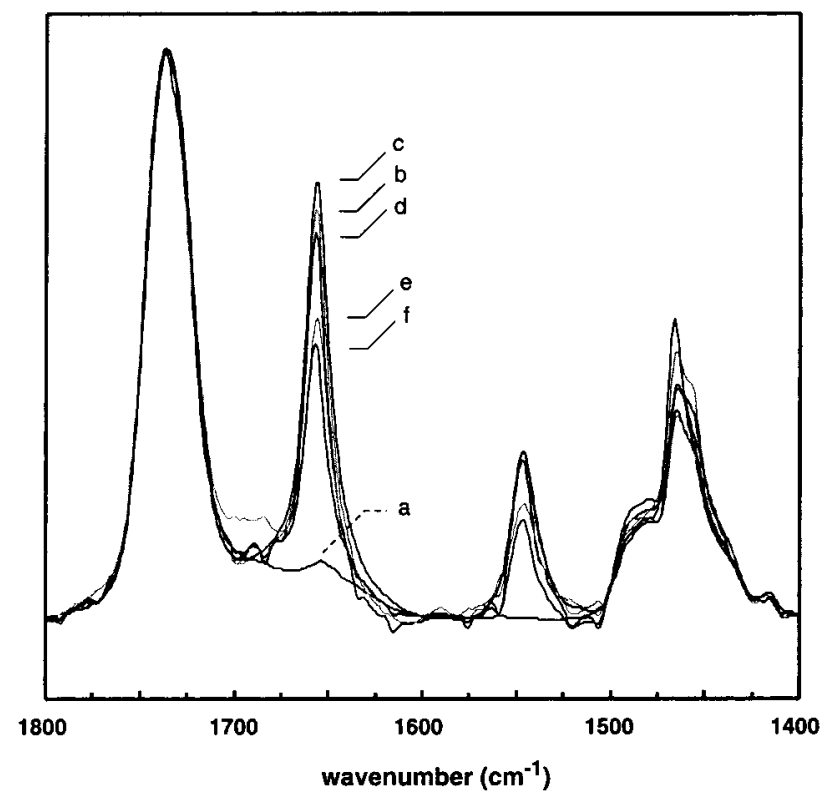

FIGURE 1: Baseline-corrected and atmospheric water-subtracted ATR-FTIR spectra of pure 16:1 1 -PC (a) and of WALP21 incorporated in bilayers of $14: 1_{\mathrm{c}}-\mathrm{PC}(\mathrm{b}), 16: 1_{\mathrm{c}}-\mathrm{PC}(\mathrm{c}), 18: 1_{\mathrm{c}}-\mathrm{PC}(\mathrm{d}), 20$ : $1_{\mathrm{c}}-\mathrm{PC}(\mathrm{e})$, and $22: 1_{\mathrm{c}}-\mathrm{PC}(\mathrm{f})$. The intensities were normalized with respect to the lipid $v(\mathrm{C}=\mathrm{O})$ vibration around $1736 \mathrm{~cm}^{-1}$ in the WALP21/16: $1_{\mathrm{c}}$-PC spectrum.

backbone can adapt its length to better match the hydrophobic bilayer thickness, a series of peptide-lipid mixtures with varying peptide length and bilayer thickness were prepared for ATR-FTIR measurements. The WALP peptides (Table 1) are uncharged and consist of a variable-length hydrophobic core of leucine and alanine residues, flanked on both sides by tryptophans. As lipid components, monounsaturated diacylphosphatidylcholine lipids with different acyl chain lengths (see Table 2) were selected because of their property to form fluid bilayers at room temperature. When WALP peptides are incorporated at a peptide/lipid molar ratio of $1 / 30$, as used in this study, all phosphatidylcholine species form lamellar bilayer structures (data not shown).

WALP/PC samples with varying peptide length and bilayer thickness were prepared as described in the Methods section, and FTIR spectra were recorded. As an example, spectra of WALP21 (an analogue of intermediate length) in bilayers of varying thickness are presented in Figure 1. The distinct spectral component around $1736 \mathrm{~cm}^{-1}$ corresponds to the lipid ester stretch vibration. At lower wavenumber, the peptide amide I and amide II vibrations and the lipid $\mathrm{CH}_{2}$ bending motion are visible, centered around 1657,1547 , and $1465 \mathrm{~cm}^{-1}$, respectively. $\mathrm{A} \mathrm{CH}_{2}$ bending contribution of the peptide is also present at $1465-1455 \mathrm{~cm}^{-1}$. The amide I vibration is the most intense polypeptide absorption band

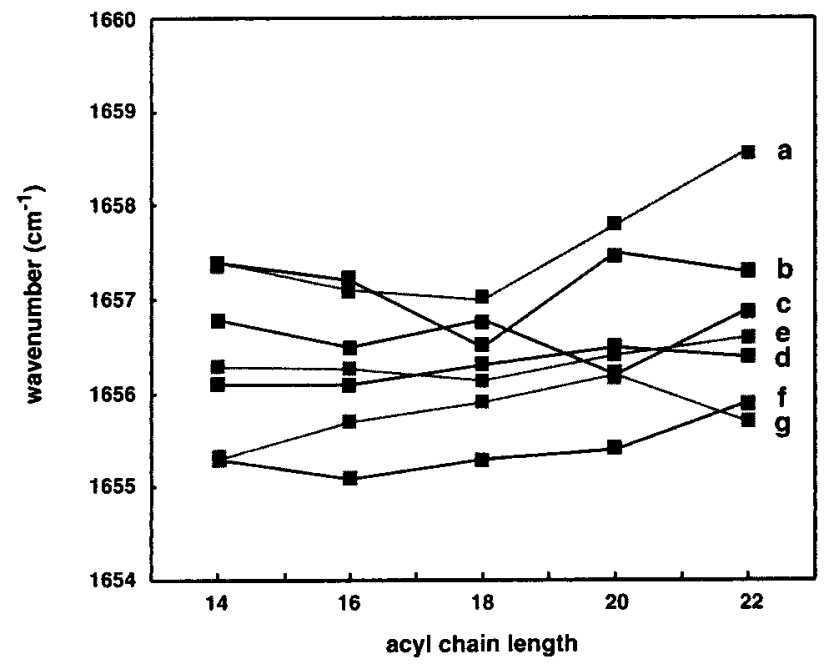

FIGURE 2: Position of amide I absorption band maximum, as determined by peak fitting procedures after subtraction of pure lipid spectra, for WALP16 (a), WALP19 (b), WALP21 (c), WALP23 (d), WALP25 (e), WALP27 (f), and WALP31 (g), in different bilayers of diacylphosphatidylcholine. The experimental error is estimated to be $0.5 \mathrm{~cm}^{-1}$.

and is mainly composed of the carbonyl vibration $v(\mathrm{C}=\mathrm{O})$ contribution from the amide bond. Because this carbonyl moiety is involved in interresidue hydrogen bonding that stabilizes protein secondary structure, its spectral position can be used to characterize backbone conformation (32). For WALP21 in all the lipid systems, the wavenumber corresponding to maximal intensity and the narrow width of the observed amide I band is characteristic of a well-defined $\alpha$-helix. This is also supported by the position of the amide II absorption band. Therefore, the conclusion can be drawn that transitions to nonhelical conformations do not occur as a result of mismatch. This was found also for all of the other measured peptide-lipid systems (spectra not shown). We will first consider the amide I positions in more detail and subsequently will address the variations in amide I intensity that can be observed in Figure 1.

To evaluate the spectra more quantitatively, the amide I peaks were curve-fitted to establish the position of the band maximum. Because also pure lipid samples absorb to a certain extent in the amide I region (see Figure 1, curve a), subtraction of pure lipid spectra was performed prior to curve fitting. The amide I maxima for all of the WALP systems are shown in Figure 2. When amide I positions of peptides with increasing length in the same bilayer are compared, in general, significant shifts (up to $3 \mathrm{~cm}^{-1}$ ) toward lower wavenumbers are encountered in each lipid system. This is not related to mismatch effects but is ascribed to the fact that longer peptides generally form more stable $\alpha$-helices that absorb at lower wavenumbers (33). The measured differences as a function of peptide length highlight the sensitivity of the ATR-FTIR method. Evaluating each peptide length analogue separately, with a few exceptions, only minor and nonsystematic changes in amide I position are observed as a function of increasing bilayer thickness. Most of the points in Figure 2 that deviate from the general trends, such as WALP16/22:1 $1_{\mathrm{c}}-\mathrm{PC}$ or WALP31 in all PC systems, correspond to low-intensity signals (see below). These are difficult to fit reliably, and therefore the deviations are likely to be spectral artifacts. Thus, it can be concluded that the 

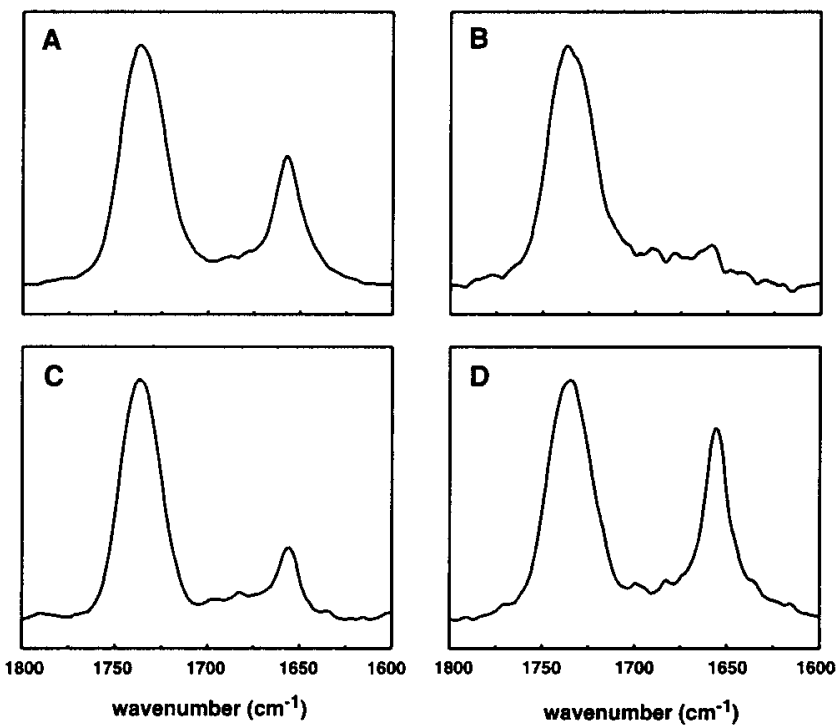

FIGURE 3: ATR-FTIR spectra representing some extreme peptidelipid combinations: (A) WALP16/14:1 1 -PC, (B) WALP16/ 22:1 - PC, (C) WALP27/14:1 1 -PC, and (D) WALP27/22:1 1 -PC.

$\alpha$-helical backbone conformation is essentially unaffected by mismatch with the host bilayer.

Fraction of Peptides Incorporated in Bilayers. In contrast to the shape and position of the amide I band, the intensity of the amide I absorption band appears to be very sensitive to the extent of peptide-bilayer mismatch. In Figure 1, a considerable decrease in intensity is observed for the samples with the longest lipids, and also some decrease is seen for the sample with the shortest lipid. This suggests that peptides that are too short (negative mismatch) or too long (positive mismatch) do not contribute as efficiently to the amide I band as do matching peptides. The same holds for the amide II intensities. A similar trend was observed in other peptidelipid systems, as illustrated in Figure 3. The amide I intensity of WALP16 in 14:1 $1_{\mathrm{c}}-\mathrm{PC}$ and in 22:1 $1_{\mathrm{c}}$-PC should be about equal because the overall peptide-to-lipid molar ratio is identical in both samples. Yet, while a clear band is seen in the former spectrum, the latter spectrum is almost equivalent to a spectrum obtained with pure lipid. In contrast, the longer analogue WALP27 causes a strongly reduced amide I intensity in the sample with the short lipid but not in the sample with the long lipid. These results indicate that both positive and negative mismatches lead to a decrease in amide I intensity. It is possible to compare the amide I intensity of all the systems by correcting for the different peptide lengths. The largest value thus obtained was set to 100, and the other values were scaled accordingly. These relative amide I intensities are reported in Table 3. Because pure peptide in water gives only a negligible FTIR signal (data not shown), presumably due to aggregation of the water-insoluble WALP peptides that visually precipitate, these data strongly suggest that less peptide becomes incorporated in the bilayer under mismatch conditions.

The precise effective hydrophobic lengths of the peptides are not known, because these will depend, e.g., on the orientations of side chains and their preferred positioning in the bilayer. However, assuming that a high relative amide I intensity (Table 3 ) indeed corresponds with closely matching WALP/PC combinations, the peptide and lipid dimensions presented in Tables 1 and 2 suggest that matching conditions
Table 3: Amide I Spectral Contributions of Peptides in

Diacylphosphatidylcholine Bilayers of Varying Thickness, Relative to Lipid Carbonyl Intensity and Corrected for the Different Number of Amide Groups in the Peptides ${ }^{a}$

\begin{tabular}{lccccc}
\hline & $14: 1_{\mathrm{c}}$-PC & $16: 1_{\mathrm{c}}-\mathrm{PC}$ & $18: 1_{\mathrm{c}}-\mathrm{PC}$ & $20: 1_{\mathrm{c}}-\mathrm{PC}$ & $22: 1_{\mathrm{c}}-\mathrm{PC}$ \\
\hline +WALP16 & 90 & 80 & 60 & 20 & 10 \\
+WALP19 & 90 & 80 & 70 & 30 & 20 \\
+WALP21 & 90 & 100 & 70 & 60 & 40 \\
+WALP23 & 90 & 80 & 60 & 60 & 50 \\
+WALP25 & 70 & 90 & 100 & 100 & 70 \\
+WALP27 & 20 & 60 & 80 & 90 & 100 \\
+WALP31 & 20 & 20 & 30 & 40 & 40
\end{tabular}

${ }^{a}$ A value of 100 represents the most intense relative amide I signal, and the experimental error is estimated to be \pm 15 .

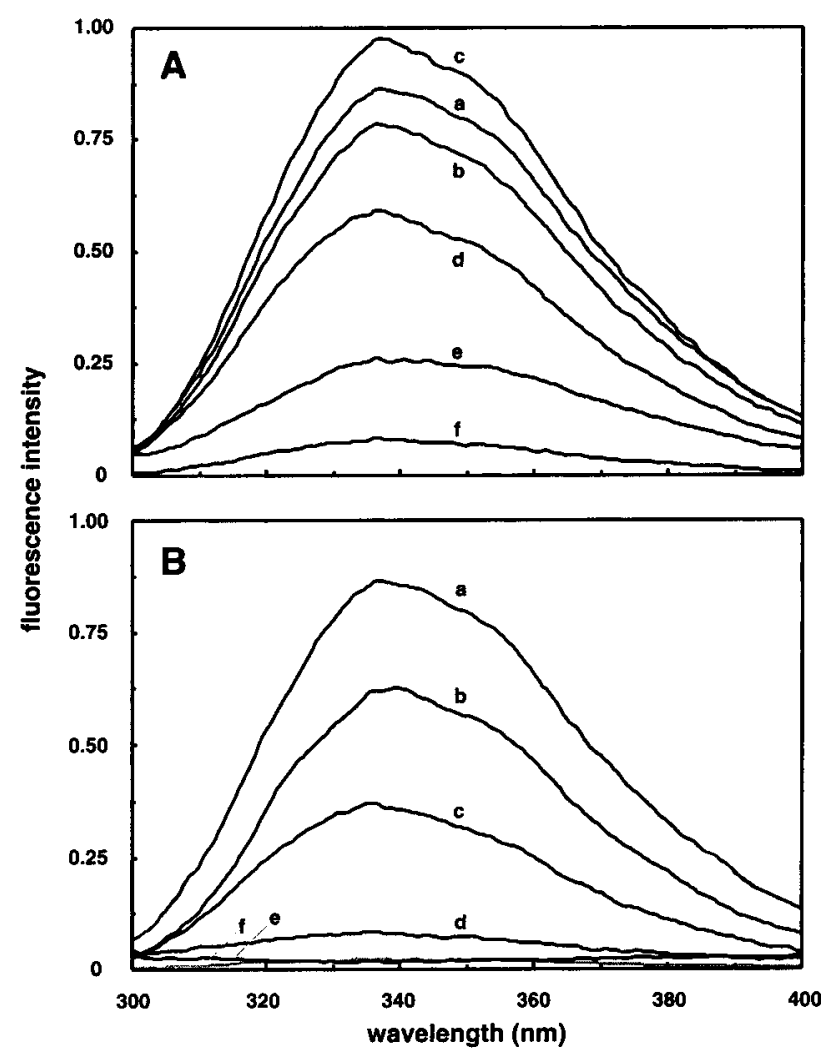

FIGURE 4: Fluorescence emission spectra of (A) WALP16 (a), WALP19 (b), WALP21 (c), WALP23 (d), WALP27 (e), and WALP31 (f) in 14:1 1 -PC and of (B) WALP16 in 14:1 1 -PC (a), 16:1 $1_{\mathrm{c}}-\mathrm{PC}(\mathrm{b}), 18: 1_{\mathrm{c}}-\mathrm{PC}(\mathrm{c}), 20: 1_{\mathrm{c}}-\mathrm{PC}(\mathrm{d}), 22: 1_{\mathrm{c}}-\mathrm{PC}(\mathrm{e})$, and $\mathrm{H}_{2} \mathrm{O}$ alone (f).

are obtained when the length of the hydrophobic Leu-Ala stretch between the Trp residues approaches the hydrophobic bilayer thickness. This is in agreement with earlier work, in which it was demonstrated that the flanking Trp residues prefer positioning near the lipid carbonyls at the polar-apolar membrane interface (19).

The interaction of the WALP peptides with lipid bilayers under mismatch conditions was further investigated by fluorescence measurements. Emission spectra of different WALP peptides incorporated in $14: 1_{\mathrm{c}}$-PC are shown in Figure 4A, and spectra of WALP16 in lipids with different acyl chain lengths are presented in Figure 4B. All the spectra are characterized by emission maxima centered around 337 $\mathrm{nm}$. This indicates that, regardless of the extent of mismatch, the tryptophan residues are in an environment that is less polar than water but more polar than the membrane 
Table 4: Composition of WALP-PC Samples with a Varying Extent of Mismatch, As Determined by Analysis of Fractions Obtained by Sucrose Density Gradient Centrifugation

\begin{tabular}{|c|c|c|c|c|}
\hline \multirow[b]{2}{*}{ sample } & \multicolumn{2}{|c|}{ low-density fraction ${ }^{a}$} & \multicolumn{2}{|c|}{ high-density fraction ${ }^{a}$} \\
\hline & $\mathrm{P} / \mathrm{L}$ & $\%$ peptide $^{b}$ & $\mathrm{P} / \mathrm{L}$ & $\%$ peptide $^{b}$ \\
\hline WALP16/14:1 1 -PC & $1 / 32$ & 94 & $-c$ & \\
\hline WALP16/22:1 $1_{\mathrm{c}}$-PC & $1 / 128$ & 23 & $1 / 9$ & 87 \\
\hline WALP27/14: $1_{\mathrm{c}}-\mathrm{PC}$ & $1 / 119$ & 25 & $1 / 12$ & 75 \\
\hline WALP27/22: $1_{\mathrm{c}}$-PC & $1 / 35$ & 86 & $-c$ & \\
\hline
\end{tabular}

${ }^{a}$ Low-density fractions, but not high-density fractions, are in a planar bilayer organization. ${ }^{b}$ Percentage of total amount of peptide in sample. ${ }^{c}$ No high-density fraction present after gradient centrifugation.

hydrophobic core, which is in agreement with the expected interfacial position of the tryptophan residues in the bilayers $(17,19)$. However, the fluorescence intensity of the WALP/ PC systems presented in Figure 4 varies strongly. Pure peptide in water yields an extremely low-intensity fluorescence signal (see Figure 4B, curve f), due to self-quenching in peptide aggregates (35), and fluorescence intensity therefore correlates with the fraction of membrane-associated peptide (17). The intensities of the different peptides in Figure 4A can be compared directly, because all of the peptides contain the same number of tryptophan residues. WALP21 displays the highest intensity in $14: 1_{\mathrm{c}}-\mathrm{PC}$, and both shorter and longer analogues have a lower intensity. In Figure $4 \mathrm{~B}$, WALP16 is seen to yield a high-intensity fluorescence signal in the shortest lipids, while the intensity gradually decreases with increasing lipid length. Thus, these data indicate that peptide-lipid combinations that have a large amide I contribution in FTIR spectra (Table 3) also show a high intensity in fluorescence spectra. Since differences between the fluorescence and FTIR intensity trends are relatively minor, both techniques clearly demonstrate the relation between peptide spectral contribution and hydrophobic mismatch.

To establish whether such reduced spectral contributions indeed reflect a reduced extent of peptide incorporation in a bilayer, the same systems as selected for Figure 3 were analyzed by sucrose density gradient centrifugation. The peptide/lipid molar ratio of resolved bands was determined as described in the Methods section, and results are shown in Table 4. Samples of WALP16/14:1 $1_{\mathrm{c}}$-PC and WALP27/ 22:1 1 -PC (peptide-lipid combinations with approximately matching hydrophobic lengths) with an overall peptide/lipid molar ratio of $1 / 30$ both yielded one clear major band on the gradient after centrifugation. In both samples, this band was characterized as a planar lipid bilayer with a peptide/ lipid ratio close to the value expected for quantitative incorporation. WALP16/22:1 $1_{\mathrm{c}}$-PC and WALP27/14:1 $1_{\mathrm{c}}-\mathrm{PC}$ samples, on the other hand, gave two clear bands after gradient centrifugation (data not shown). The low-density upper bands consisted of peptide-depleted bilayers, while the high-density lower bands were highly peptide enriched (see Table 4). Solid-state ${ }^{31} \mathrm{P}$ NMR $(36,37)$ showed that these high-density bands were represented by ill-defined broad "isotropic" ${ }^{31}$ P NMR spectra (data not shown). This suggests the presence of amorphous lipid assemblies, although a more defined lipid organization cannot be ruled out. In any case, these results confirm that the extent of WALP peptide incorporation reflects the extent of mismatch with the bilayer. Whether a peptide is too short or too long with respect to bilayer thickness, the tolerated amount of incorporated peptide is reduced, and the bilayer-excluded peptide is present in aggregates that also contain some lipid material. As shown in Table 4, the peptide fraction that is incorporated in the gradient-separated bilayers corresponds well with the peptide fraction that contributes to the amide I FTIR intensity (Table 3).

The results suggest that, upon hydration of peptide-lipid mixtures, peptides are segregated out of the bilayer when their hydrophobic length is too short or too long to fit into the lipid bilayer. If this is indeed the case, then the observed effects should not depend on the way peptides and lipids are brought together during the sample preparation. We verified this by investigating the influence of several commonly used variations in the sample preparation methods on fluorescence intensity of WALP-PC systems (see Methods). For samples prepared with the mixed film method, fluorescence intensities were similar when the peptide-lipid film was dried from other solvents, such as pure TFE or pure ethanol (data not shown). Also, when dried peptidelipid mixtures were obtained by lyophilization from an aqueous dispersion and hydrated as a powder (as in ref 19) rather than as a dried film, qualitatively similar results were obtained, as illustrated by the emission intensities at $337 \mathrm{~nm}$ (compare panels A and B of Figure 5). The additional blueshifted peak around $310 \mathrm{~nm}$ that is observed upon large negative mismatch (e.g., WALP16/22:1c-PC), may, considering the higher intensity in this region of pure WALP in water, represent excluded peptide aggregates, possibly with some lipids. Adding an excess of water to a concentrated solution of peptide and lipid in ethanol $(18,38)$, rather than to dried peptide-lipid mixtures, surprisingly resulted in high fluorescence intensities for mismatching WALP-PC combinations (Figure 5C). This discrepancy is probably related to the fact that ethanol dilution does not result in the formation of multilamellar vesicles but in the formation of small unilamellar vesicles (38). The high curvature of these vesicles might inhibit segregation into peptide-rich aggregates and promote the positioning of mismatching peptides in the interface, oriented parallel to the membrane surface, which for WALP peptides will also give rise to a high-intensity fluorescence signal around $337 \mathrm{~nm}$. Such a method-dependent expression of transmembrane stability has indeed been demonstrated for short Lys-flanked peptides $(17,18)$. In conclusion, different sample preparation procedures that result in the initial formation of extended lipid bilayers show a consistent relation between WALP-PC mismatch and extent of incorporation.

Tilt Angle with Respect to Bilayer Normal of Relatively Long Peptides. Although the main effect of a large positive mismatch with Trp-flanked peptides is a decrease in the amount of incorporated peptide, some peptide is clearly present in the membrane. In this situation, a tilt of relatively long peptides could assist in additionally relieving a hydrophobic mismatch. To study the orientation of the WALP peptides by parallel and perpendicular (with respect to the incidence plane) polarized IR light, a host membrane is required that forms well-oriented bilayers on a solid support. 14:0-PC was selected because its orientation properties are better than those of the unsaturated lipids and because its short acyl chains enable the creation of systems with a positive mismatch. Relative amide I intensities of the peptides 


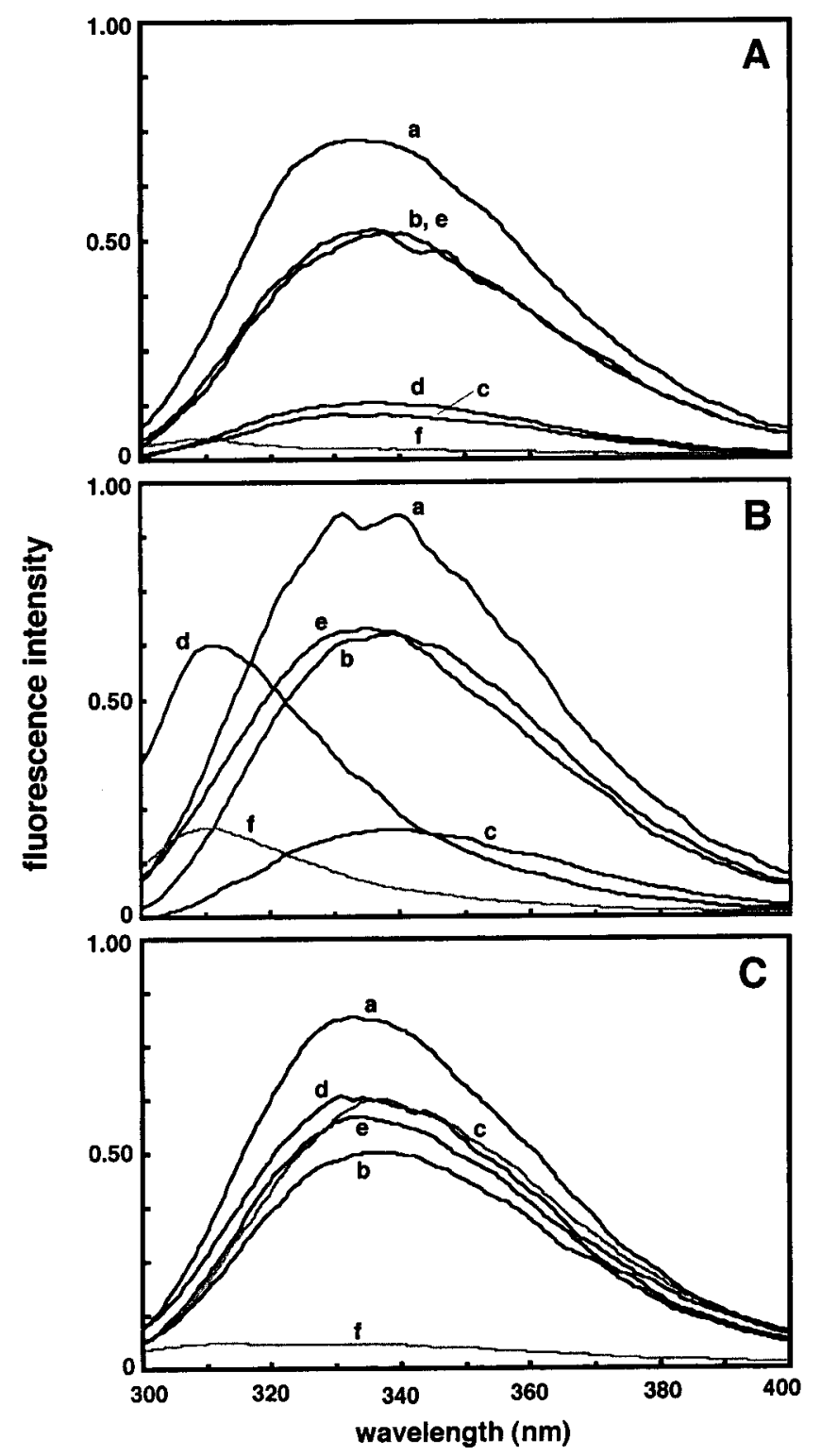

FIGURE 5: Fluorescence emission spectra of WALP16/14:1 $1_{\mathrm{c}}-\mathrm{PC}$ (a), WALP23/14:1 1 -PC (b), WALP27/14:1 ${ }_{\mathrm{c}}$-PC (c), WALP16/22: $1_{\mathrm{c}}-\mathrm{PC}(\mathrm{d}), \mathrm{WALP} 27 / 22: 1_{\mathrm{c}}-\mathrm{PC}(\mathrm{e})$, and pure WALP23 (f) dispersions prepared by the (A) mixed film method from TFE and methanol, (B) lyophilization method, and (C) ethanol dilution method.

in 14:0-PC (data not shown) depended on mismatch and closely resembled the values found for $16: 1_{\mathrm{c}}-\mathrm{PC}$, which forms bilayers with almost the same thickness as 14:0-PC (Table 2). Figure 6 shows parallel and perpendicular polarized spectra of an intermediate-length (WALP21) and a long (WALP27) peptide in 14:0-PC. In the WALP21 spectra, the parallel contribution is clearly much stronger than the perpendicular contribution, indicating that the helix axis is oriented almost parallel to the bilayer normal. For WALP27, the perpendicular component is still the weaker one, but it has gained in relative intensity. This could correspond to a helix with a significantly larger tilt angle with respect to the bilayer normal. Because unincorporated peptide does not significantly contribute to the spectrum, the dichroism data specifically describe the orientation of the membrane-associated peptides. However, it cannot be ruled out that this larger perpendicular spectral contribution is caused by a fraction of helices that are oriented along the membrane surface.
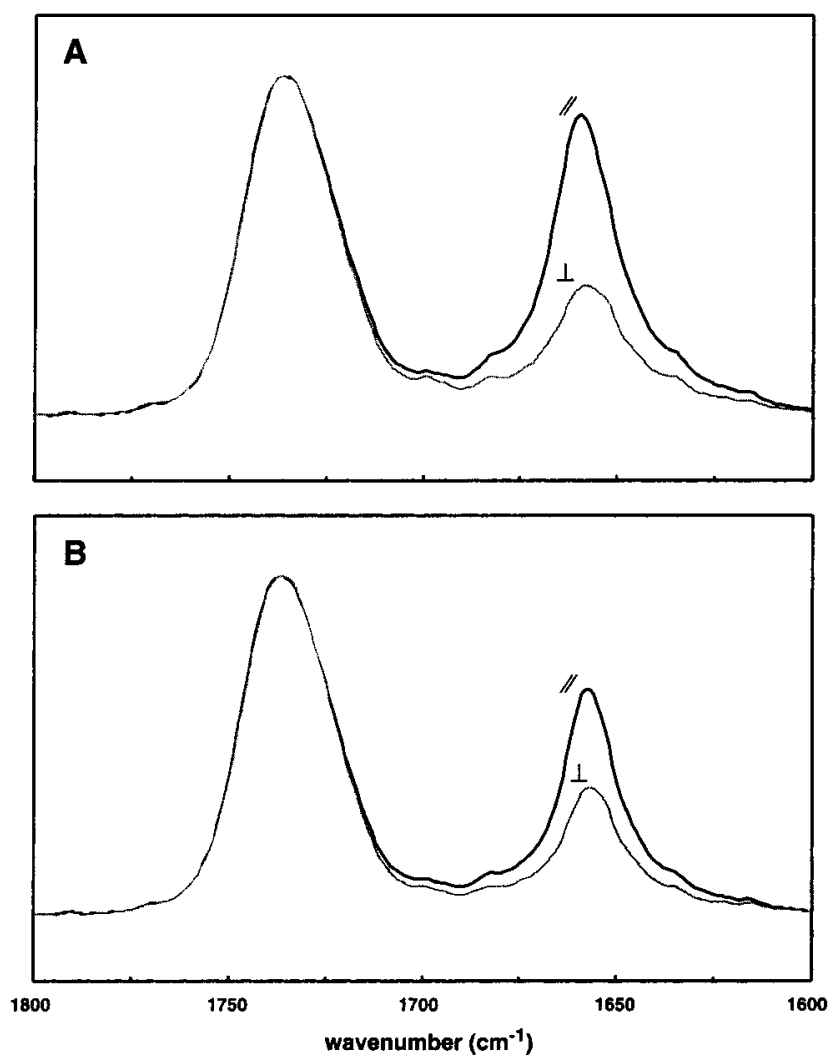

FIGURE 6: Parallel (II) and perpendicular $(\perp)$ polarized ATR-FTIR dichroic spectra of (A) WALP21 and (B) WALP27 in 14:0-PC.

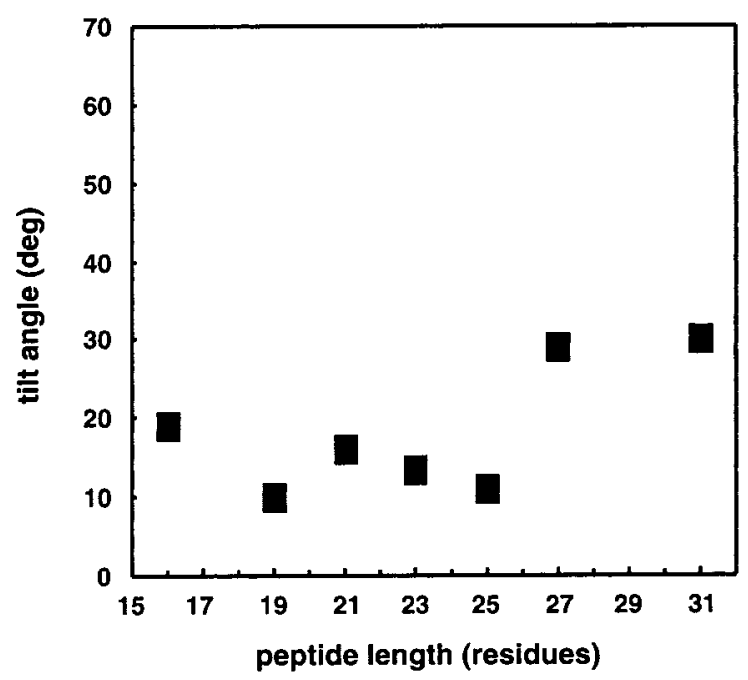

FIGURE 7: Maximum tilt angles of peptide helix axis with respect to the membrane normal of WALP analogues in 14:0-PC. The values shown are the average of three experiments, with an error of \pm 5 deg.

Maximum tilt angles for the different WALP analogues were computed, assuming complete ordering of the bilayer stacks, and are presented in Figure 7. The data suggest that the peptides that are expected to have a significant positive mismatch in 14:0-PC (WALP27-31) are tilted, while the peptides that are nearly matching or are relatively short in 14:0-PC all have much smaller tilt angles. If a slight disorder would be present in the bilayer stacks, these latter angles are reduced to close to zero. Because it is unlikely that the bilayer stacks are completely ordered, it can be concluded that WALP16-25 are probably oriented parallel to the 


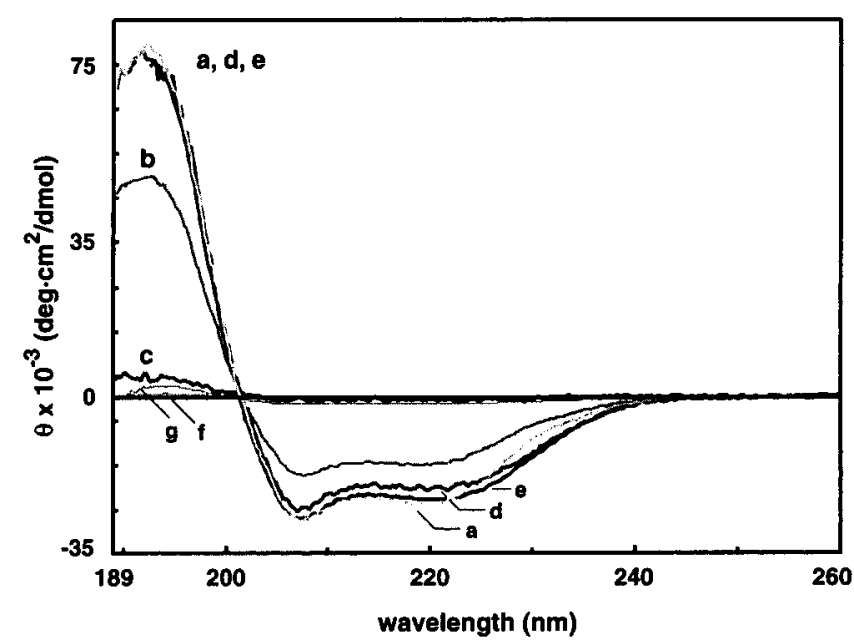

FIGURE 8: Circular dichroism spectra of WALP23 (a), WALP27 (b), WALP31 (c), KALP23 (d), and KALP31 (e), in 14:0-PC and of pure WALP23 (f) and KALP23 (g) in aqueous solution. Spectral intensity is presented as mean residue ellipticity.

membrane normal, and the maximum possible increase in tilt angle for WALP27-31 is probably approximately 10$20 \mathrm{deg}$.

Different Incorporation Properties of Trp-Flanked and Lys-Flanked Peptides. Webb et al. (17) and Ren et al. (18, 38) demonstrated in membrane model systems that Lysflanked polyleucine peptides, with one Trp reporter group at a varying position in the Leu stretch and with a Gly residue adjacent to the C-terminal pair of Lys residues, flanking the hydrophobic stretch, do not incorporate in a transmembrane fashion in phosphatidylcholine bilayers that are relatively thick. However, these peptides totally incorporate in bilayers that are relatively thin. The latter observation contrasts sharply with the results for long WALP peptides that are obtained in the present study. To establish whether this different behavior is due to the presence of the Lys flanking groups, or to other sequence differences between both peptide families, we synthesized relatively long KALP peptides, which are similar to the WALP peptides, except that all Trp residues have been replaced by Lys residues (see Table 1).

WALP peptides are insoluble in aqueous solution, while the more polar relatively long KALP analogues are soluble in pure water but insoluble in salt solution. Consequently, to ensure that only the membrane-associated KALP peptide fraction is detected, KALP-PC systems should contain salt, but this disables measurements on deposited membrane films as employed in ATR-FTIR spectroscopy. Therefore, and because KALP analogues do not contain a fluorescent moiety, we used circular dichroism spectra to directly compare WALP and KALP incorporation in a relatively thin bilayer. Under these conditions, also with this technique no significant intensity is observed in the absence of lipids (see Figure 8, curves $\mathrm{f}$ and $\mathrm{g}$ ), and hence intensity correlates with the extent of membrane association. Resultant spectra are presented in Figure 8. As deduced from the minima near 222 and $208 \mathrm{~nm}$, the crossover at $202 \mathrm{~nm}$, and the maximum near $192 \mathrm{~nm}$, all peptides are in the anticipated $\alpha$-helical conformation (39). The spectral intensities indicate that the total amount of WALP23, KALP23, and KALP31 (curves a, d, e) associates with a 14:0-PC bilayer. The longer WALP27 analogue (curve b) does not completely solubilize in the bilayer, and almost none of the WALP31 peptide (curve c) is associated with the membrane. These experiments clearly demonstrate that relatively long Lys-flanked and Trpflanked peptides display different bilayer interactions and that these different properties are imposed entirely by the nature of the flanking residues.

\section{DISCUSSION}

Observed versus Theoretical Consequences of PeptideBilayer Hydrophobic Mismatch. If hydrophobic matching between transmembrane protein fragments and lipid bilayers constitutes an important interaction factor in membrane systems, it can be expected that hydrophobic mismatch could have a significant effect on membrane organization. A number of membrane responses can be envisaged that could theoretically relieve a mismatch situation in a binary peptide-lipid system (reviewed in ref 14).

It is shown in this study that, despite the many membrane adaptations that potentially could occur, the main response of the membrane system to mismatch situations is the exclusion of peptide material from the planar bilayer. From the results obtained with FTIR, fluorescence, circular dichroism, and sucrose density gradient centrifugation, it is evident that when either negative or positive mismatch is increased, the fraction of peptide that is incorporated in the bilayer is reduced. We use the term "incorporation" exclusively to refer to the amount of peptide that is found to be incorporated in the bilayer and not to refer to an equilibrium process in which a peptide partitions between the membrane and the aqueous phase, as studied with water-soluble peptides (40). The peptides used in the present study appear to be insoluble in an aqueous environment, which enables the unambiguous assignment of the membrane-associated peptide fraction. This insolubility also makes it unlikely that peptide exchange occurs between the membrane and the aqueous phase once the membrane has been formed. The most likely scenario is that in the dried film lipids and peptides are well mixed in a bilayer, from which peptides with unfavorable membraneassociating properties are desorbed during hydration. Such a mechanism is supported by the observation that the extent of peptide incorporation appears to be independent of the method of sample preparation. Most of this extramembranous peptide is present in lipid-containing aggregates that are not detectable by spectrophotometric techniques. These assemblies do not give rise to defined ${ }^{31} \mathrm{P}$ NMR spectra, and therefore they most likely represent amorphous structures, although it cannot be excluded that more regular unknown structures are formed. Previously, it was shown that peptides that are too short to fit in a bilayer can in principle be accommodated in well-defined nonlamellar structures, such as the inverted hexagonal phase (30). The particular geometry of this phase allows positioning of the peptides in a way that effectively counteracts the mismatch. However, the formation of this phase by short peptides in PC dispersions requires significantly higher peptide/lipid ratios than were used in the present study. The inverted hexagonal phase that is formed becomes highly enriched in peptide, leaving part of the lipids in a bilayer that is peptide-depleted but still contains some peptides (30).

As shown in the present study, the amount of peptide that can be accommodated in a bilayer depends on the extent of 
mismatch. Under mismatch conditions, a small amount of peptide is incorporated, and in this case it is possible that adaptations within the bilayer do indeed occur. One response that is expected to be energetically favorable is segregation of mismatching membrane components, or peptide aggregation $(12,41)$. However, previous ESR measurements did not indicate a mismatch-induced aggregation of WALP peptides (24). Another possible adaptation is a (dis)ordering of the flexible lipid acyl chains. This adaptation does occur, as was demonstrated by ${ }^{2} \mathrm{H}$ NMR-detected changes in bilayer thickness (24). But although these changes systematically reflected the imposed extent of mismatch, the absolute values were not sufficiently large to relieve entirely the peptidelipid mismatch (24). In this study we investigated therefore whether a conformational change of the peptide backbone might occur as an additional membrane response. IR spectroscopy is the most sensitive technique to measure hydrogen bond lengths [in the case of amide $\mathrm{I}$, a $1 \mathrm{~cm}^{-1}$ shift corresponds to a change of only about $30 \mathrm{cal} / \mathrm{mol}$ of the enthalpy of hydrogen bond formation $(32,42)]$. The lack of dependence of the amide I peak position on mismatch, as established in the present IR study (Figure 2), argues against even partial backbone transitions from the very stable $\alpha$-helix to a shorter $\pi$-helix or a longer $33_{10}$-helix. Together, these results indicate that a minor WALP-PC mismatch can be tolerated. For peptides that are slightly too long, another remaining transmembranous peptide arrangement that would allow complete hydrophobic matching is a tilted backbone, which has been predicted to be a favorable mismatch response $(17,18)$ and which has been observed for membrane proteins with multiple membrane-spanning segments (e.g., ref 43). The FTIR dichroic spectra (Figure 6) are indeed indicative of a small mismatch-dependent peptide tilt, but a significant effect is observed only at a large positive mismatch. Apparently, tilt can occur, but for the WALP analogues it is not favored since the main system response is a strongly reduced extent of incorporation. A possible explanation is that for single-spanning peptides a tilt would disturb the packing of the surrounding lipids, which is energetically unfavorable. In multiple-spanning proteins tilt may be more favorable because the disruption of membrane packing caused by tilt of one helix could be compensated by tilt in the opposite direction of a second helix.

Flanking Residues and Hydrophobic Mismatch: Different Effects of Trp and Lys. The question can be raised whether the observed responses to hydrophobic mismatch are general for transmembrane segments or whether they depend on the nature of the flanking residues. Several groups have established the consequences of mismatch between PC bilayers and Lys-flanked polyleucine or poly(leucine-alanine) peptides that may have a Trp residue in the middle of the sequence as a fluorescent reporter group. The results of these various studies suggested that Lys-flanked peptides in many ways behave in a fashion similar to that of Trp-flanked peptides. They do not form ESR-detectable large aggregates in the bilayer (44), although rhodamine self-quenching of rhodamine-labeled peptides indicated that there is some degree of oligomerization of longer peptides (18). Furthermore, the peptide long axis is oriented approximately parallel to the bilayer normal $(16,20)$, and the peptide backbone is not sensitive to variations in thickness of fluid bilayers (45). Lys-flanked peptides can influence bilayer thickness $(15,46)$ and, at high concentration, are also able to induce the formation of nonlamellar phases in PC (19). At relatively low concentration, too short Lys-flanked analogues do not incorporate in a bilayer $(17-20,38)$. In these aspects, systems with Lys-flanked peptides thus appear to behave rather similarly to systems with Trp-flanked analogues. However, there are also some interesting differences between both peptide families.

One difference concerns the effective hydrophobic length of both types of peptide. Previously, we compared the exact changes in membrane conformation that are induced by a Lys-flanked peptide, KALP23, with the effects caused by an equisized Trp-flanked analogue, WALP23. It was found that the two peptides incorporate equally well but influence membrane thickness to different extents and induce dissimilar nonlamellar phases. From these observations, it was concluded that Lys as the flanking residue imparts a peptide with a slightly smaller effective hydrophobic length than Trp as the flanking residue. The results indicated that the mismatch-induced membrane rearrangements for these peptides are aimed at keeping the Trp side chain located exclusively at the polar-apolar membrane interface and at keeping the Lys side chain positioned in a less well-defined region closer to the aqueous phase (19).

As shown in this study, another difference between Trpflanked and Lys-flanked analogues is their tendency to incorporate in PC bilayers. Relatively long KALP peptides remain incorporated in bilayers, while equisized WALP peptides do not. The observation that long Lys-flanked peptides incorporate completely (Figure 8; see also refs 17 , 18, and 38) without an appreciable backbone tilt (16) suggests that the entire headgroup region is an appropriate environment for a Lys side chain. This is in agreement with experiments in which the partitioning of small unstructured host peptides between bulk water and a PC membrane-water interface was measured; Lys-containing peptides favored (and Trp-containing analogues disfavored) residing in the aqueous phase (47). Also, the observation that Lys-flanked KALP peptides are water soluble while Trp-flanked WALP peptides are not soluble in aqueous solution (19) supports the notion that Lys side chains can interact with the entire waterpenetrated headgroup region. Alternatively or additionally, the flexibility of the long Lys side chain could facilitate positioning of the terminal charge in a favorable membrane environment $(48,49)$. Thus, Lys-flanked peptides may require a much larger total length than Trp-flanked analogues to be effectively too long in a membrane. Indeed, recent solid-state ${ }^{31} \mathrm{P}$ and ${ }^{15} \mathrm{~N}$ NMR measurements on Lys-flanked peptides in oriented PC bilayers showed that, at extreme positive mismatch, the peptide alignment is disturbed together with the bilayer alignment, indicating that also Lys-flanked peptides can be effectively too long in a membrane (20).

Biological Significance: Mismatch in Biological Membranes. Complex biological membranes might display a somewhat larger tolerance to mismatch than simple model membranes, because lipids with favorable acyl chain lengths could preferentially surround (mis)matching protein segments. However, the range of available acyl chain lengths will limit such a response. Extrapolating the outcomes of model membrane studies, it can therefore be expected that also in biological membranes the extent of hydrophobic mismatch determines protein incorporation. Recently, it was 
suggested that the presence of aromatic flanking residues buffers transmembrane segments against changes in bilayer thickness (50). The present study demonstrates that Trp residues impart transmembrane domains with very welldefined hydrophobic lengths that could influence whether a protein incorporates in a membrane or not, depending on bilayer hydrophobic thickness. Peptides or small proteins might flip out of the membrane as a consequence of large mismatch, but for large proteins with extensive extracellular domains, this is more difficult to envisage. However, large proteins could be laterally expelled from the mismatching bilayer environment and cluster into domains together with mismatching lipid components. Such domains could then be expelled from the membrane and thereby might play a role in protein and lipid sorting in the cell.

Indeed, hydrophobic matching has been explicitly proposed as a sorting and retention mechanism for proteins in the secretion pathway $(9,10)$. This was based on the observation that lengthening and shortening of the transmembrane domain of Golgi resident proteins (e.g., sialyltransferase) can influence compartment localization $(51,52)$. In the present study on WALP peptides in model membrane systems, a strict correlation between hydrophobic matching and peptide incorporation has indeed been found, in support of the view that hydrophobic matching by itself could regulate protein sorting in the secretion pathway. For Lysflanked analogues the same may be true, as was proposed previously $(17,38)$. However, in the present study as well as in previous studies $(17,38)$, it could not be demonstrated that too long Lys-flanked peptides fail to associate with a membrane. We propose that, due to the larger side chain flexibility, (much) longer Lys-flanked peptides are required to obtain an effective mismatch that could disfavor membrane incorporation. Additionally, our results suggest that Trp side chains impart a transmembrane segment with a better defined effective length than Lys side chains and could therefore result in a more pronounced sorting behavior. When many aromatic and positively charged residues are simultaneously present in a transmembrane segment (with the charged residues positioned closer to the aqueous phase than the aromatic residues), this arrangement should result in an even better defined hydrophobic length. This type of flanking motif is, for instance, found in the transmembrane segment of sialyltransferase (51), a protein that is strictly confined to the Golgi apparatus, despite the continuous flow of protein that is transported through the Golgi to specific (extra)cellular locations.

Finally, as another implication of our results, it can be expected that protein displacement parallel to the membrane normal will tend to be opposed by Trp residues, because these tend to maintain interactions with the polar-apolar membrane interface. For transmembrane domains that are flanked by the long and flexible Lys side chain, the effective hydrophobic length will be less well defined, and lysine will impose less positional restrictions on a transmembrane segment than tryptophan. Experiments on the interfacial positioning of mutant transmembrane helices of leader peptidase in the endoplasmic reticulum membrane, as analyzed by the so-called glycosylation mapping technique $(53,54)$, have indeed yielded evidence that the Trp side chains can guide the placement of a transmembrane protein segment in a membrane, while Lys side chains can position the terminal charge in a favorable membrane region even when the Lys $\mathrm{C}^{\alpha}$ group is located deeper within the membrane ("snorkling" conformation).

\section{ACKNOWLEDGMENT}

We thank Gerda de Korte for HPLC analysis.

\section{REFERENCES}

1. Johannsson, A., Smith, G. A., and Metcalfe, J. C. (1981) Biochim. Biophys. Acta 641, 416-421.

2. Montecucco, C., Smith, G. A., Dabbeni-sala, F., Johansson, A., Galante, Y. M., and Bisson, R. (1982) FEBS Lett. 144, $145-148$.

3. Lee, A. G. (1998) Biochim. Biophys. Acta 1376, 381-390.

4. Carruthers, A., and Melchior, D. L. (1988) Annu. Rev. Physiol. $50,257-271$.

5. Dumas, F., Tocanne, J.-F., Leblanc, G., and Lebrun, M.-C. (2000) Biochemistry 39, 4846-4854.

6. Sperotto, M. M., and Mouritsen, O. G. (1993) Eur. Biophys. J. 22, 323-328.

7. Lehtonen, J. Y. A., and Kinnunen, P. K. J. (1997) Biophys. J. 72, 1247-1257.

8. Dumas, F., Sperotto, M. M., Lebrun, M.-C., Tocanne, J.-F., and Mouritsen, O. G. (1997) Biophys. J. 73, 1940-1953.

9. Pelham, H. R. B., and Munro, S. (1993) Cell 75, 603-605.

10. Munro, S. (1998) Trends Cell Biol. 8, 11-15.

11. Mouritsen, O. G., and Bloom, M. (1984) Biophys. J. 46, 141153.

12. Mouritsen, O. G., and Bloom, M. (1993) Annu. Rev. Biophys. Biomol. Struct. 22, 145-171.

13. Dumas, F., Lebrun, M. C., and Tocanne, J.-F. (1999) FEBS Lett. 458, 271-277.

14. Killian, J. A. (1998) Biochim. Biophys. Acta 1376, 401-416.

15. Huschilt, J. C., Hodges, R. S., and Davis, J. H. (1985) Biochemistry 24, 1377-1386.

16. Zhang, Y.-P., Lewis, R. N. A. H., Henry, G. D., Sykes, B. D., Hodges, R. S., and McElhaney, R. N. (1995) Biochemistry $34,2348-2361$.

17. Webb, R. J., East, J. M., Sharma, R. P., and Lee, A. G. (1998) Biochemistry 37, 673-679.

18. Ren, J., Lew, S., Wang, J., and London, E. (1999) Biochemistry $38,5905-5912$

19. De Planque, M. R. R., Kruijtzer, J. A. W., Liskamp, R. M. J., Marsh, D., Greathouse, D. V., Koeppe, R. E., II, De Kruijff, B., and Killian, J. A. (1999) J. Biol. Chem. 274, 20839-20846.

20. Harzer, U., and Bechinger, B. (2000) Biochemistry 39, 1310613114.

21. Landolt-Marticorena, C., Williams, K. A., Deber, C. M., and Reithmeier, R. A. F. (1993) J. Mol. Biol. 229, 602-608.

22. Doyle, D. A., Cabral, J. M., Pfuetzner, R. A., Kuo, A., Gulbis, J. M., Cohen, S. L., Chait, B. T., and MacKinnon, R. (1998) Science 280, 69-77.

23. Von Heijne, G. (1986) EMBO J. 5, 3021-3027.

24. De Planque, M. R. R., Greathouse, D. V., Koeppe, R. E., II, Schäfer, H., Marsh, D., and Killian, J. A. (1998) Biochemistry 37, 9333-9345.

25. Greathouse, D. V., Koeppe, R. E., II, Providence, L. L., Shobana, S., and Andersen, O. S. (1999) Methods Enzymol. 294, 525-550.

26. Goormaghtigh, E., Raussens, V., and Ruysschaert, J.-M. (1999) Biochim. Biophys. Acta 1422, 105-185.

27. Bechinger, B., Ruyssschaert, J.-M., and Goormaghtigh, E. (1999) Biophys. J. 76, 552-563.

28. Marsh, D. (1999) Biophys. J. 77, 2630-2637.

29. Picard, F., Buffeteau, T., Desbat, B., Auger, M., and Pézolet, M. (1999) Biophys. J. 76, 539-551.

30. Killian, J. A., Salemink, I., De Planque, M. R. R., Lindblom, G., Koeppe, R. E., II, and Greathouse, D. V. (1996) Biochemistry 35, 1037-1045.

31. Rouser, G., Fleischer, S., and Yamamota, A. (1970) Lipids 5, 494-496. 
32. Goormaghtigh, E., Cabiaux, V., and Ruysschaert, J.-M. (1994) Subcell. Biochem. 23, 329-362.

33. Nevskaya, N. A., and Chirgadze, Y. N. (1976) Biopolymers $15,637-648$.

34. Lewis, B. A., and Engelman, D. M. (1983) J. Mol. Biol. 166, $211-217$.

35. Jones, O. T., and Lee, A. G. (1985) Biochemistry 24, 21952202.

36. Seelig, J. (1978) Biochim. Biophys. Acta 515, 105-140.

37. Cullis, P. R., and De Kruijff, B. (1979) Biochim. Biophys. Acta $559,399-420$.

38. Ren, J., Lew, S., Wang, Z., and London, E. (1997) Biochemistry 36, 10213-10220.

39. Greenfield, N., and Fasman, G. D. (1969) Biochemistry 8, 4108-4116.

40. Wimley, W. C., and White, S. H. (2000) Biochemistry 39, 4432-4442.

41. Gil, T., Ipsen, J. H., Mouritsen, O. G., Sabra, M. S., Sperotto, M. M., and Zuckermann, M. J. (1998) Biochim. Biophys. Acta 1376, 245-266.

42. Tonge, P. J., and Carey, P. R. (1992) Biochemistry 31, $9122-$ 9125.

43. Le Coutre, J., Narasimhan, L. R., Patel, C. K. N., and Kaback, H. R. (1997) Proc. Natl. Acad. Sci. U.S.A. 94, 10167-10171.
44. Subczynski, W. K., Lewis, R. N. A. H., McElhaney, R. N., Hodges, R. S., Hyde, J. S., and Kusumi, A. (1998) Biochemistry $37,3156-3164$.

45. Zhang, Y.-P., Lewis, R. N. A. H., Hodges, R. S., and McElhaney, R. N. (1995) Biochemistry 34, 2362-2371.

46. Nezil, F. A., and Bloom, M. (1992) Biophys. J. 61, 11761183.

47. Wimley, W. C., and White, S. H. (1996) Nat. Struct. Biol. 3, $842-848$.

48. Mishra, V. K., Palgunachari, M. N., Segrest, J. P., and Anantharamaiah, G. M. (1994) J. Biol. Chem. 269, 71857191.

49. Mishra, V. K., and Palgunachari, M. N. (1996) Biochemistry $35,11210-11220$.

50. Mall, S., Broadbridge, R., Sharma, R. P., Lee, A. G., and East, J. M. (2000) Biochemistry 39, 2071-2078.

51. Munro, S. (1991) EMBO J. 10, 3577-3588.

52. Munro, S. (1995) EMBO J. 14, 4695-4704.

53. Braun, P., and Von Heijne, G. (1999) Biochemistry 38, 97789782.

54. Killian, J. A., and Von Heijne, G. (2000) Trends Biochem. Sci. 25, 429-434.

BI000804R 